\title{
EFFECTIVENESS OF ACCEPTANCE AND COMMITMENT THERAPY (ACT) ON DYSFUNCTIONAL COMMUNICATIVE ATTITUDE (DCA) OF COUPLES SUFFERING DIABETES IN BANDAR ABBAS
}

\author{
Azita Amirfakhraei \\ Ph.D Student of Health Psychology, Department of Psychology, Kish International Branch, Islamic Azad \\ University, Kish Island, Iran \\ Hassan Ahadi \\ Professor, Department of Psychology, AllamehTabatabai University, Tehran, Iran \\ Adis Keraskian \\ Assistant Professor, Department of Psychology, KarajBranch, Islamic Azad University, Karaj, Iran \\ Javad Khalatbare \\ Associate Professor, Department of Psychology, Tonekabon Branch, Islamic Azad University, \\ Tonekabon, Iran
}

\begin{abstract}
Introduction: This study aimed to examine the effectiveness of ACT on the DCA of couples suffering diabetes in Bandar Abbas.

Methods: This is applied in terms of purpose and regarding the method, it is quasi-experimental done by Solomon Four-Group design. The population of this study is all diabetic patients of Bandar Abbas, to select the sample, first notes of holding training sessions related to this study in counseling centers, other related institutes in Bandar Abbas were hung, and the candidates were registered.Then, based on entry criteria (including a definite diagnosis of diabetes by a physician, diabetes type 2, being married, and the age range of 20-50 years), 80 volunteers to participate in the workshop, were randomly divided into six groups of experiment and control this means for each intervention 20 patients and in the control group 20 patients were assigned randomly.Data were collected through relationships beliefs questionnaire (RBQ; Romance \&Deboard, 1995). The experimental group received 8 sessions (1.5 hour) of couple therapy.

Results: The results showed that ACT affects DCA of the couples $(\mathrm{P}<0.001, \mathrm{~F}=33.95)$.

Conclusion:ACT significantly improves couple's communication attitudes and sexual satisfaction of the diabetes.patients
\end{abstract}

Keywords: Acceptance and Commitment Therapy Introduction, dysfunctional communicative attitude

\section{INTRODUCTION}

Diabetes is the most common metabolic disorder and according to somepeople the most common endocrine disease (Anderewli, Greeks, Kolchak, Mine, 2012). The disease is of lasting illnesses caused by turbulence of starchy carbohydrate metabolism (Jamshidi, 2012). This disease like any other chronic disease makes problems for the patients and affects all aspects of a person's life. The person with diabetes haspsychological and social problems due to dietary restrictions that cause health complications such as kidney problems, eye, heart, brain, and sexual disorders. One of the major complications of diabetes is problems associated with wife (Najafi et al., 2006) and can be so severe that lead to depression and anxiety in patients with diabetes (Sousa et al., 2004). Some disturbances such as sexual dysfunction (Tavalaeeet al., 2010), low quality of life (Monjamed et al., 2006), anxiety and depression (Befroui et al., 2014) are common in diabetics. Recent studies have shown that both intrapersonal factors including personal characteristics, feedback, beliefs, values and expectations and interpersonal issues such as love, 
intimacy, commitment, emotion and sexuality, communication patterns and family issues affect marital satisfaction. Thus, the existence of the chronic illness diabetes in one spouse, due to creating sexual dysfunction, causes marital boredom, affects DCA, and ultimately lack of marital satisfaction (Asadi et al., 2013).

Today, different approaches of couples therapy and family therapy have been developed aimed at reducing conflicts and confusion in communication between couples. The aim of couple therapy is to help the couples to better cope with the current problems and learning more effective communication methods (Davarniya et al., 2015).

Dysfunctional marriage attitudes aredocumentary styles, couples understanding from each other and the family environment that may cause seriously damage relations of the family (Yonsei and Bahrami, 2008).

One of the third wave approaches is behavior therapy that includes hybrid methods of metaphor, paradox skills, and mental focus on psychological interventions. Its theoretical framework is cognitive-intellectual theory and includes the process of acceptance and commitment and psychological flexibility behavior change (Honarparvaran, 2012).

Greg, Kalaghan, and Hayes (2007) performed a study on diabetic patients and it was shown that the use of acceptance and understanding skills (Intelligence) is effective in controlling the negative thoughts and feelings related to diabetes.

Alamdari (2013) determined the effectiveness of ACT on marital satisfaction and quality of life of infertile couples. The results of multivariate analysis of variance (MANOVA) showed that ACTaffects marital satisfaction and quality of life $(\mathrm{P}<0.001)$.

These results indicate that ACT can moderate some problems of infertile couples. In fact, this training in infertile group focuses on experiential avoidance and acceptance throughtraining essential skills such as mindfulness.

Heydariyanfar (2013) studied the effectiveness of ACT in reducing psychological distress, interpersonal distress and the acceptance and practice of mindfulness, quality of marital couple's communication dysfunctional attitudes inDezful. The study population included all the couplesin clinic Psychological Education Department in 2013inDezful. The results showed that ACT has a positive impact on all the variables studied,and this impact is more on variables of psychological distress, interpersonal, adopt, and practice.

Greg, Kalaghan and Hayes (2007) assessed the efficacy ACTin increasing the quality of life and life satisfaction and DCAof cancer patients, and the results of their study showed that post-test scores had a significant reduction in signs of psychological problems.

KarkolandConstantino (2010) in a study concluded that people who have cancer, before participating in ACT chosestrict procedures ways of dealing with the problem, while after attending ACT, they dealt with difficulties and disabilities caused by cancerflexibly and with mind-consciousness.

In a study by Masuda, et al(2009), the relationship between psychiatric flexibility and mental health in ACT showed that improving in the mental health of participants in the intervention and follow-upgroups.

Longmore and Worl (2007), in separate studiesof evaluating the efficacy of ACTin Generalized Anxiety Disorder concluded that ACT is effective for treating this disorder.

Block (2002) showed that the use of mindfulness methodasits basic element like ACT is effective for the treatment of anxiety disorders. 
Zettle and Hayes (1986) in a study aboutthe efficiency of ACT in reducing depression have shown that people who were treated with ACT showed significant decrease in depressive symptoms compared to the control group.

Education based on acceptance and commitment is efficient in improving DCA of diabetic couples.

\section{METHODS AND RESEARCH TYPE}

The present study is an experimental research conducted with the aim of showing solution-based training efficiency in marital satisfaction and attitudes of couples suffering diabetes. This was a quasiexperimental study (of Solomon four groups design).

The population of this study is all diabetic patients of Bandar Abbas, to select the sample, first notes of holding training sessions related to this study in counseling centers, other related institutes in Bandar Abbas were hung, and the candidates were registered.

The sample size and method of measurement: After selecting people based on based on entry criteria (including a definite diagnosis of diabetesby a physician, diabetes type 2, being married, and the age range of 20-50 years), 80 volunteers to participate in the workshop, were randomly divided into six groups of experiment and control this means for each intervention 20 patients and in the control group 20 patients were assigned randomly. The experimental and control groups took pretest before the intervention of couples' marital satisfaction and dysfunctional attitudes and approaches to carry out the intervention sessions for each group based on the post-test was performed after the meetings.

Research Tools:Relationships beliefs questionnaire (Romance \&Deboard, 1995) RBQ is one of the relatively widely used scales to measure thoughts and irrational beliefs and dysfunctional marital relationship that is developed to understand the relationships of couples, the place of cognitive mediation in emotional reactions and behavior of couples in marital relations and also to understand the nature and meaning of their interactions. Several studies (Romance Debord, 1995; Debord and others, 1996) conducted to assess the validity of RBQ especially through factor analysis showed that the scale has nine factors. 1) totally honest and tolerance for each other at all times, 2) read the thoughts of each other, 3) do everything together, 4) satisfying all the needs, 5) the ability and willingness to change ourselves for another, 6) everything'sbeing perfect within the marriage, 7) ease of maintaining good marital relations, 8) perfect romantic relationships, and 9) romanticism.Results of the validation of agents extracted from RBC scale, in the study by Azkhosh andAskari (2007) for test-retest reliability, internal consistency with one month distance were 0.945 and 0.925 respectively. The results show that the set of scale has proper accuracy, reliability, repeatability, and reliability. This is such that we can trust the results frommeasuring the effectiveness of the results of its interventions and counseling, as well as future studies and research in related areas. RBQ correlation with Jones Irrational Beliefs Test (1968) confirmed its convergent validity $(\mathrm{r}=0.32, \mathrm{P}>0.001)$. The content structure of this factors substantially aligned with Alice's theory (1991, 2001).

\section{FINDINGS}

Frequency distribution and percentage of the sample group in terms of demographic characteristics are reported in Table 1.

Table 1. The demographic characteristics of subjects

\begin{tabular}{lll}
\hline Variables & Percent & Frequency \\
\hline Man & 50 & 40 \\
Female & 50 & 40 \\
Married for & 0.10 & 8 \\
5 years & 25.46 & 37 \\
\hline
\end{tabular}




\begin{tabular}{lll}
\hline 6-10years & 25.41 & 33 \\
$\begin{array}{l}\text { 11-15 years } \\
\text { more than }\end{array}$ & 5.2 & 2 \\
15 years & 0.0 & 0 \\
No reply & & \\
Age $29-36$ & 75.3 & 3 \\
37-44 & 75.73 & 59 \\
$45-52$ & 0.10 & 8 \\
No reply & 0.0 & 0 \\
\hline
\end{tabular}

Statistical Inference of Data:Before testing research hypotheses the sameness of the two experimental groups and reliability of the tests used in this study present and normal distribution of data were examined. For comparison, the average duration of marriage and age of four categories each of the treatments, ANOVA test was used. Results are reported in tables 2 and 3.

Table 2: Summary of analysis of variance to compare the duration of marriage

\begin{tabular}{ccccccc}
\hline & $\begin{array}{c}\text { Source of } \\
\text { changes }\end{array}$ & $\begin{array}{c}\text { Sum of } \\
\text { squares }\end{array}$ & $\begin{array}{c}\text { Degrees } \\
\text { of } \\
\text { freedom }\end{array}$ & Mean Square & F & $\begin{array}{c}\text { Significance } \\
\text { level }\end{array}$ \\
\hline $\begin{array}{c}\text { ACT } \\
\text { Acceptance and } \\
\text { Commitment } \\
\text { Therapy ACT }\end{array}$ & Intergroup & 28.250 & 3 & 9.417 & 0.856 & 0.468 \\
\hline
\end{tabular}

Table 3: Summary analysis of variance to compare age

\begin{tabular}{|c|c|c|c|c|c|c|}
\hline & $\begin{array}{l}\text { Mean } \\
\text { Square }\end{array}$ & $\begin{array}{c}\text { Degrees } \\
\text { of } \\
\text { freedom }\end{array}$ & $\begin{array}{l}\text { Sum of } \\
\text { squares }\end{array}$ & $\begin{array}{c}\text { Source of } \\
\text { changes }\end{array}$ & $\begin{array}{c}\text { Significance } \\
\text { level }\end{array}$ & $\mathrm{F}$ \\
\hline \multirow[t]{3}{*}{$\mathrm{ACT}$} & 11.779 & 3 & 35.337 & Intergroup & 0.412 & 0.968 \\
\hline & 12.165 & 76 & 924.550 & Intragroup & $\begin{array}{c}\text { Significance } \\
\text { level }\end{array}$ & \\
\hline & & 79 & 959.878 & Total & 0.412 & \\
\hline
\end{tabular}

Given that the F index calculated (in both variables in all three studies) is smaller than critical index F0.05with the stated degree of freedom so with 95 percent confidence the null hypothesis stating the equality of average duration of marriage and age of the subjects in four research groups in all three studies is confirmed.

Research result:In solutions based on subgroups of gender, duration of marriage and age are homogeneous.Given that the validity of the test is dependent on the sample, before data analysis and hypothesis testing, to ensure the accuracy of the results, internal consistency of the test used in the study was estimated using Cronbach's alpha coefficient. The results of these indicsare reported in Table 4. 
Table 4. The internal consistency of the instruments used in this study $(20=n)^{1}$

\begin{tabular}{rccc}
\hline & $\begin{array}{l}\text { Average } \\
(Z \text { Fisher })\end{array}$ & ACT & \\
\hline $\begin{array}{r}\text { Dysfunctional } \\
\text { communication } \\
\text { attitude }\end{array}$ & $\mathbf{0 . 9 7 7}$ & 0.957 & 0.988 \\
$\begin{array}{r}\text { questionnaire } \\
\hline\end{array}$ & & & \\
\hline
\end{tabular}

The above results indicate the validity and acceptable internal consistency to use this research tool in the community and sample to measure the relevant variables.

Kolmogorov-Smirnov test shows the normal distribution of research data. The results are reported in Table 5 separatelyrelated to marital satisfaction and DCA.

Table 5: Results Kolmogorov-Smirnov test to study the normality of DCA data

\begin{tabular}{|c|c|c|c|c|c|}
\hline & & & Average & $\begin{array}{c}\text { The standard } \\
\text { deviation }\end{array}$ & $\begin{array}{c}\text { Z Index } \\
\text { (Significance } \\
\text { level) }\end{array}$ \\
\hline & Group & $\begin{array}{c}\text { Running } \\
\text { time }\end{array}$ & 90.70 & 16.61 & $\begin{array}{c}0.409 \\
(0.996) \\
\end{array}$ \\
\hline & \multirow{2}{*}{$\begin{array}{c}\text { Pre-test - } \\
\text { post-test and } \\
\text { treat }(n=20)\end{array}$} & pre-test & 182.08 & 13.97 & $\begin{array}{c}0.524 \\
(0.947)\end{array}$ \\
\hline & & Post-test & 112.90 & 6.26 & $\begin{array}{c}0.923 \\
(0.362) \\
\end{array}$ \\
\hline \multirow[t]{4}{*}{$\begin{array}{l}\text { Pre-test - } \\
\text { post-test } \\
\text { and treat } \\
(\mathrm{n}=20) \\
\end{array}$} & \multirow[t]{2}{*}{ pre-test } & pre-test & 110.18 & 5.73 & $\begin{array}{c}1.006 \\
(0.264)\end{array}$ \\
\hline & & Post-test & 184.80 & 8.97 & $\begin{array}{c}0.408 \\
(0.996) \\
\end{array}$ \\
\hline & $\begin{array}{l}\text { Post-test with } \\
\text { treatment } \\
(\mathrm{n}=20)\end{array}$ & pre-test & 68.43 & 14.42 & $\begin{array}{c}1.184 \\
(0.121)\end{array}$ \\
\hline & $\begin{array}{l}\text { Post-test with } \\
\text { treatment } \\
(20=\mathrm{n})\end{array}$ & Post-test & Average & $\begin{array}{c}\text { The standard } \\
\text { deviation }\end{array}$ & $\begin{array}{c}\text { Z Index } \\
\text { (Significance } \\
\text { level) }\end{array}$ \\
\hline
\end{tabular}

Given that significance level of $\mathrm{z}$ index calculated (in both variables in the triple therapy group, four groups and two runs times) is larger than 0.05 , so the null hypothesis of no difference of data distribution with normal distribution is confirmed with $95 \%$ level of confidence.

Research result: data distribution is a normal distribution

${ }^{1}$ The fourth group study to assess the reliability data (post-test without treatment) is intended to be independent of the effect of pre-test results and treatment. 
Table 6.Summary of two-way univariate analysis of variance[Based on acceptance and commitment DCA]

\begin{tabular}{|c|c|c|c|c|c|}
\hline Sources of Change & $\begin{array}{l}\text { Sum of } \\
\text { squares }\end{array}$ & $\begin{array}{l}\text { Degrees } \\
\text { of } \\
\text { freedom }\end{array}$ & $\begin{array}{l}\text { Mean } \\
\text { Square }\end{array}$ & $\mathrm{F}$ & $\begin{array}{l}\text { Effect size } \\
\text { Partial eta } \\
\text { squared } \eta 2 \\
\end{array}$ \\
\hline The corrected pattern & 194742.259 & 3 & 64914.086 & 502.871 & \\
\hline Width from origin & 1487714.878 & 1 & 1487714.878 & 11524.500 & \\
\hline Treatment (test / control) & 177237.378 & 1 & 177237.378 & $* * 1373.007$ & 0.948 \\
\hline $\begin{array}{l}\text { Pre-test (with pre-test / without post- } \\
\text { test) }\end{array}$ & 7614.753 & 1 & 7614.753 & $* * 58.858$ & 0.437 \\
\hline $\begin{array}{l}\text { Interaction between treatment and pre- } \\
\text { test }\end{array}$ & 9890.128 & 1 & 9890.128 & $* * 76.616$ & 0.502 \\
\hline Error & 9810.612 & 76 & 129.087 & & \\
\hline total & 1692267.70 & 80 & & & \\
\hline Total corrected & 204552.872 & 79 & & & \\
\hline
\end{tabular}

Interaction between treatment and pre-test:Given that the $\mathrm{F}$ indicator calculated (76.616) is larger than F0.01 with degrees of freedom 76 and 1 (6.96), so the null hypothesis of equality of means with $99 \%$ confidence is rejected. In other words, the average post-test score of DCA in four groups of ACT have significant difference with each other.

Table 7. The results of two independent groups [based on acceptance and commitment - DCA]

\begin{tabular}{|c|c|c|c|c|c|c|c|c|c|c|}
\hline & & \multirow{2}{*}{ Frequency } & \multirow{2}{*}{ Mean } & \multirow{2}{*}{ SD } & $\begin{array}{l}\text { Variances } \\
\text { sameness }\end{array}$ & \multicolumn{5}{|c|}{ Test of average of two independent groups } \\
\hline & & & & & $\mathrm{F}$ & $\begin{array}{c}\text { Mean } \\
\text { difference }\end{array}$ & $\begin{array}{c}\text { The standard } \\
\text { error of } \\
\text { difference }\end{array}$ & $d f$ & $\mathrm{t}$ & $\begin{array}{l}\text { Size } \\
\text { of } \\
\text { effect }\end{array}$ \\
\hline \multirow{2}{*}{$\begin{array}{r}\text { With } \\
\text { pre-test }\end{array}$} & Experiment & 20 & 155.30 & 5.40 & \multirow{2}{*}{0.543} & \multirow{2}{*}{28.60} & \multirow{2}{*}{1.543} & \multirow{2}{*}{38} & 18.539 & \multirow{2}{*}{0.900} \\
\hline & Control & 20 & 126.70 & 4.29 & & & & & $* *$ & \\
\hline \multirow{2}{*}{$\begin{array}{l}\text { Without } \\
\text { pre-test }\end{array}$} & Experiment & 20 & 184.80 & 8.97 & \multirow{2}{*}{1.020} & \multirow{2}{*}{116.38} & \multirow{2}{*}{3.797} & \multirow{2}{*}{38} & 30.646 & \multirow{2}{*}{0.961} \\
\hline & Control & 20 & 68.43 & 14.42 & & & & & $* *$ & \\
\hline
\end{tabular}

- With pre-test:Given that the $t$ indicator calculated (18.539) is larger than t0.01 with 38 degrees of freedom in one range test (2.423), so the null hypothesis of equality of means of DCA in post-test with two groups that have pre-test is rejected with $99 \%$ confidence. In other words, DCA mean of the group that received ACT (155.30) was significantly higher than the group that did not receive ACT (126.70).

Without pre-test:Given that the $t$ indicator calculated (30.646) is larger than t0.01 with 38 degrees of freedom in one range test (2.423), so the null hypothesis of equality of means of DCA in post-test with two groups that have pre-test is rejected with $99 \%$ confidence. In other words, DCA mean of the group that received ACT (184.80) was significantly higher than the group that did not receive ACT (68.43).

Research results:ACT approach is effective in reduction of diabetic couples DCA. 


\section{CONCLUSION}

The present study was conducted with the aim of examining the effectiveness of DCA of couples suffering diabetes in Bandar Abbas.

Hypothesis: ACTis effective in reducing DCA of diabetic couples. The mean of DCA of the group that received ACT (178.63) was significantly higher than the group that did not receive treatment (78.53) and this is consistent with the results of Honarparvar et al (2010) Heydariyanfar (2013) Alamdari (2013) Greg, Kalaghan and Hayes (2007) Karkla, and Konstantino (2010) Masuda et al (2009) Longmore and Worl (2007) Block (2002) andZettle and Hayes (1986). In explaining the effect of ACT onDCA, it can be said thatACT is creating mental flexibility, i.e. the ability to create a practical choice among different options that are more appropriate,rather than merely to avoid thoughts, feelings, memories and agitatingdesires that are imposedon the person (Izadi and Abedi, 2013). In this treatment, at first, it is tried to increase mental acceptance of the person about subjective experiences (thoughts, feelings and...) and decrease ineffective control actions.

In addition, patients are taught that any action to prevent or control these mental experiences are ineffective or counterproductive and exacerbate it, and that these experience should be accepted with no internal or external reaction to remove them. In the second step, for Psychologicalawareness the person is added at the moment i.e. hebecomes aware of all mental states, thoughts and behavior at present.

In the second stage, the personsare taught to separate themselves from the subjective experiences (cognitive isolation) to act independently of the experiences. Fourth, efforts to reduce excessive focus on self-objectification or personal story as a victim that person has made for himself in his mind and fifth, helping the persons to know themselves and clearly make it known values and convert themto special behavioral goals (specifying values).Finally, it is creating motivation to act responsibly towards specified goals and values of activities with the adoption of subjective experience. These subjective experiences can be depressing thoughts, obsessive thoughts related to events (trauma), social anxieties and phobias, and so on.

\section{REFERENCES}

Alamdari, A. (2013). Assessing the effectiveness of acceptance and commitment therapy based on marital satisfaction and quality of life of infertile couples. Master's thesis, Faculty of Education and Psychology, University of MohagheghArdebili.

Azkhosh, M., \&Asgari, A. (2007). Measuring irrational beliefs in marriage (to standardize communication Beliefs Questionnaire), 4 (14), 39-53.

Davarniya.,\&Zahrakar., \& Mo'ayyeri., \&Shakarami. (2015). Reviewing the effectiveness of couple therapy group therapy in reducing marital burnout. Tehran University of Medical Sciences. 25 (2), 134146.

Corey, Marianne Schneider.,\& Corey, Gerald. (1999). Group Therapy. Translation: Saif Ali Bahari, B. Ranjbar and Hamid Reza Shah drafts, the owner of Mir Hashem and SiamakNaghshbandi. Tehran: Ravan Publication.

Golmohammadi, M., \&Kimiyayi, A., \& Amin Yazdi, A. (2012). Group counseling focused on solutions and its effectiveness excitation academic and goal orientation in students with academic failure. MA thesis, Ferdowsi University.

Heydariyanfar, N. (2013). The effectiveness of treatment based on acceptance and commitment therapy distressed couples. Master's thesis, Faculty of Education and Psychology ShahidChamran University of Ahvaz.

Honarparvaran, N. (2012). The effectiveness of acceptance and commitment therapy (ACT) on forgiveness and marital adjustment of women affected by marital infidelity. men and society (sociology former women). Journal of Woman and Society, 5 (3), 135-150.

Izadi, F., \&Abedi, M. (2013). Acceptance and Commitment Therapy. Tehran: Jangal publications. 
Javanmir, L., \&Kimiyayi, A., \&Ghanbari, B. (2011). Evaluating the effectiveness of group counseling based on solution focused on reducing depression in adolescents. MA thesis, Ferdowsi University.

MazloumBefroui N., \&DehghaniFiroozabadi, T., \&Alizadeh, B. (2014). Prevalence of anxiety and depression in diabetic patients. Journal of Diabetes Nursing and Midwifery. Zabol, 2 (4), 60-68.

Monjamed, Z., \&Aliasgharpour, M., \&Mehran, A., \&Peymani, T. (2006). Quality of life in patients with chronic complications of diabetes. Faculty of Nursing and Midwifery. Tehran University of Medical Sciences. 12 (1), 55-66.

Najafi, M., \& Mir Hossein M., \&MoghaniLankarani, M., \&Asari, Sh. (2006). Correlation between marital satisfaction and sexual dysfunction in patients with diabetes. Journal of Endocrinology and Metabolism, 8 (2), 175-179.

Shafiabadi, A., \&Moein, L., \&Vaghef, V. (2010). Comparing the effectiveness of the two approaches interaction (TA) and solution-focused change the level of marital satisfaction in married women working. Tehran: Women Quarterly and Society. The first year, the third number. 1(3).

Younes, J., \&Bahrami, F. (2008). The couple's marital satisfaction and deterministic thinking. Journal of Iranian Psychologists, Issue (19), 241-250. 